\title{
The air we breathe: is it safe for children?
}

\author{
Manouri P Senanayake ${ }^{1}$ \\ Sri Lanka Journal of Child Health, 2004; 33: 64-72
}

(Key words: air pollution, children, Sri Lanka)

Cholmondely Chalmers de Silva, born on 25th February 1904, commenced his medical studies in the Ceylon Medical College but proceeded to Kings College Hospital London two years later, where he completed his studies. He was appointed the first Professor of Paediatrics in this country in 1949. He occupied the chair in Paediatrics in Colombo until his retirement in 1966. During this period his untiring efforts obtained 'swaraj' for Paediatrics in the hospital sector as well as within the university system. As a researcher, Prof. C. C. was the first Ceylonese to publish in the British Quarterly Journal of Medicine and in the same year, 1948, his first article appeared in the British Medical Journal.

Professor C. C. was a wide angled clinician with many firsts to his name, such as the first reported case of thalassaemia and of kwashiorkor in this country. This list is long. Professor C. C, the social worker, helped found the Thalagolle Nutrition Rehabilitation Centre and was a staunch activist in family planning work in the 1950's. His writing skills unfold in two book-length biographical style writings "Out Steppes a Don" and "Life as I lived it". As an educationalist Professor C.C. de Silva had a vision way ahead of his times. This is evident in his farewell lecture entitled "What's wrong with you and me" delivered to medical students of both Colombo and Peradeniya. Referring to the then pass rate of $28 \%$ at the 'Finals', Professor C. C. de Silva recommended introducing continuous assessment, small group discussions and limiting lecture hours to enable more time in the wards. It was only in 1994 that the Faculty in Colombo implemented these across the board. The pass rate at the finals is now over $95 \%$.

I belong to a generation that went through medical school after the retirement of Professor C. C. de Silva. What link I may claim to his teachings and endeavours are those that percolated through the first group of medical students who came under his tutelage. It was to the 'batch of 1950' that Professor

C. C. de Silva delivered his inaugural lecture from the newly created Chair in Paediatrics. "Professor C. C's" charisma is amply attested to by the fact that of the six girls in this batch, three proceeded to become, themselves, outstanding paediatricians of international repute. Priyani de Mel who as Prof. Priyani Soysa, was his successor and my guru, Nellie Perera, who distingui-shed herself in the University of Kuwait, and Dr. Rajeswari Rajakariyar, the well known paediatrician, are here tonight to commemorate their teachers.

When a second year medical student in 1974 the then retired professor set me a short case on himself. He expected me to diagnose gouty arthritis of his big toe at a social gathering. I failed the test. I am deeply grateful to the Council for affording me this opportunity to honour this pioneering academic.

\section{History of air pollution}

Clean air is essential for good health. Air quality first drew the attention of the medical profession during the infamous London smog of $1952^{1}$. On December 5 th 1952, a dense fog formed in the centre of London and within three days, hospital bed occupancy had hit an all time high. The sudden, sharp increase in deaths, by 4000 , in the greater London Area, which was engulfed by the fog, further dramatized the link between air pollution and health. The rise in mortality due to respiratory, cardiovascular and other illdefined illnesses, was most evident in those under one year and over 45 indicating that the health impact of air pollution was mainly on children and the elderly $^{2}$ (Table 1).

More recently and closer home, on 2nd December 1984, the release of a gas cloud (methyl-isocyanate) caused what is termed the world's worst industrial catastrophe, in Bhopal. A grim reminder of just how dangerous and deadly the air we breath can become!

\footnotetext{
${ }^{1}$ Professor and Head, Department of Paediatrics, University of Colombo.
} 
Table 1

Deaths registered in Greater London - December $1952^{2}$
(Week of fog and previous week)

\begin{abstract}
$<1-14$
Week ending 6th December

Week ending 13th December

Ratio of 13th / 6th

$\begin{array}{ll}\frac{\mathbf{2 8}}{\mathbf{5 4}} & 10 \\ \underline{1.9} & 13 \\ & 1.3\end{array}$

Since 1952 an avalanche of scientific research has provided independently validated, confirmatory evidence on the adverse health effects of fine particles and noxious gases in the air. The quality of air is deteriorating in many cities, due to uncontrolled urbanisation, industrialisation, and motorization. The World Health Organization attributes 150,000 premature deaths to outdoor air pollution each year, with lung cancer increasing by $8 \%$, cardiovascular disease by $6 \%$ and all case mortality by $4 \%{ }^{3}$. Even more staggering is the global scale estimate of 2.5 million deaths each year due to indoor air pollution. Despite these figures, indoor pollution remains a neglected area in most developing countries ${ }^{4}$.
\end{abstract}

\section{Children and the environment}

The terms "pollution" and "environment" are becoming increasingly linked. In the life sciences, environment is defined as "the sum of external influences acting upon the organism". No child can do without an environment but rapid infrastructural development and changing life styles have altered the environment of the 21 st century child. Taken in its broadest context, the child's environment consists of four overlapping spheres - physical, chemical, biological and psycho-social environments. The atmosphere is the environmental factor that is most dispersed. It affects climate, plants, biodiversity as well as human health. Our concern this evening is The Quality of air in Colombo and its effects on children.

Had an oration on environment been delivered in the time of Professor C. C. de Silva, undoubtedly the focus of attention would have been the biological environment. Fifty years ago, numbers of children suffering from communicable diseases, on a given day, outnumbered children with all disease conditions today. In the mid 20th century the conquest of infectious disease appeared close at hand with the discovery of penicillin and other potent antibiotics. The United States Secretary of State even declared
Age (years)

$\begin{array}{rrrr}15-44 & 45-64 & 65-74 & 75+ \\ 61 & \underline{\mathbf{2 3 7}} & 254 & 355 \\ 99 & \underline{\mathbf{6 5 2}} & 717 & 949 \\ 1.6 & 2.8 & 2.8 & 2.7\end{array}$

imminent victory over infections at a medical congress in 1948. But man's interference with the environment has caused the battle against microbes to continue. Today urbanization, transportation and industrialization have added inanimate agents that are equally adept at causing disease to infections that are persisting, re-emerging and newly emerging. Noxious gases and heavy metals remain insidious in the environment and strike ill-health on individuals or communities.

\section{Air pollutants}

The air we breathe is a mixture of gases. The seven best known air pollutants are suspended particulate matter(SPM), lead $(\mathrm{Pb})$, sulfur dioxide (SO2), oxides of nitrogen (NOx), carbon monoxide, ozone, aromatic and other hydrocarbons. The two most important of these in developing countries are lead and SPM.

\section{Current status of air pollution in Colombo}

Concerns expressed are with particular reference to vehicle related pollutants. In the past 30 years the vehicle population in Sri Lanka has shown an exponential increase and so has the fuel consumption - far exceeding the growth rate of the human population! (Figure 1) Of the total active vehicle fleet of Sri Lanka $60 \%$ plies within the Colombo metropolitan police area making Colombo the most polluted place within Sri Lanka ${ }^{5}$. The first evidence in Colombo's biosphere was provided by a reduction in lichen coverage of trees within the city limits. Lichen accumulates sulfur in thalli and is a sensitive bio-monitor of atmospheric sulfur dioxide. 1994 saw ambient air quality standards gazetted in Sri Lanka. Since then, Continuous Air Quality Monitoring, using fully automated units, have recorded pollutant levels exceeding WHO stipulated safety standards at many locations in the city. The current average resident exposure to particulate matter in Colombo is $54 \mu \mathrm{g} / \mathrm{m}^{3}$, Fort Station being a hotspot ${ }^{6}$. These 
recordings are however comfortingly lower than in many other capital cities in the region. In Dhaka, Kathmandu and New Delhi, suspended particulate matter (SPM 10) reaches levels between 150-200 $\mu \mathrm{g} /$ cubic metre ${ }^{7}$. Colombo has not reached a crisis level yet. The bad news, however, is that (according to an environmental economist of the World Bank) the current level of exposure is estimated to cause 50 excess deaths, 1000 chronic lung diseases and 3 million episodes of acute respiratory illness each year in Colombo ${ }^{6}$.

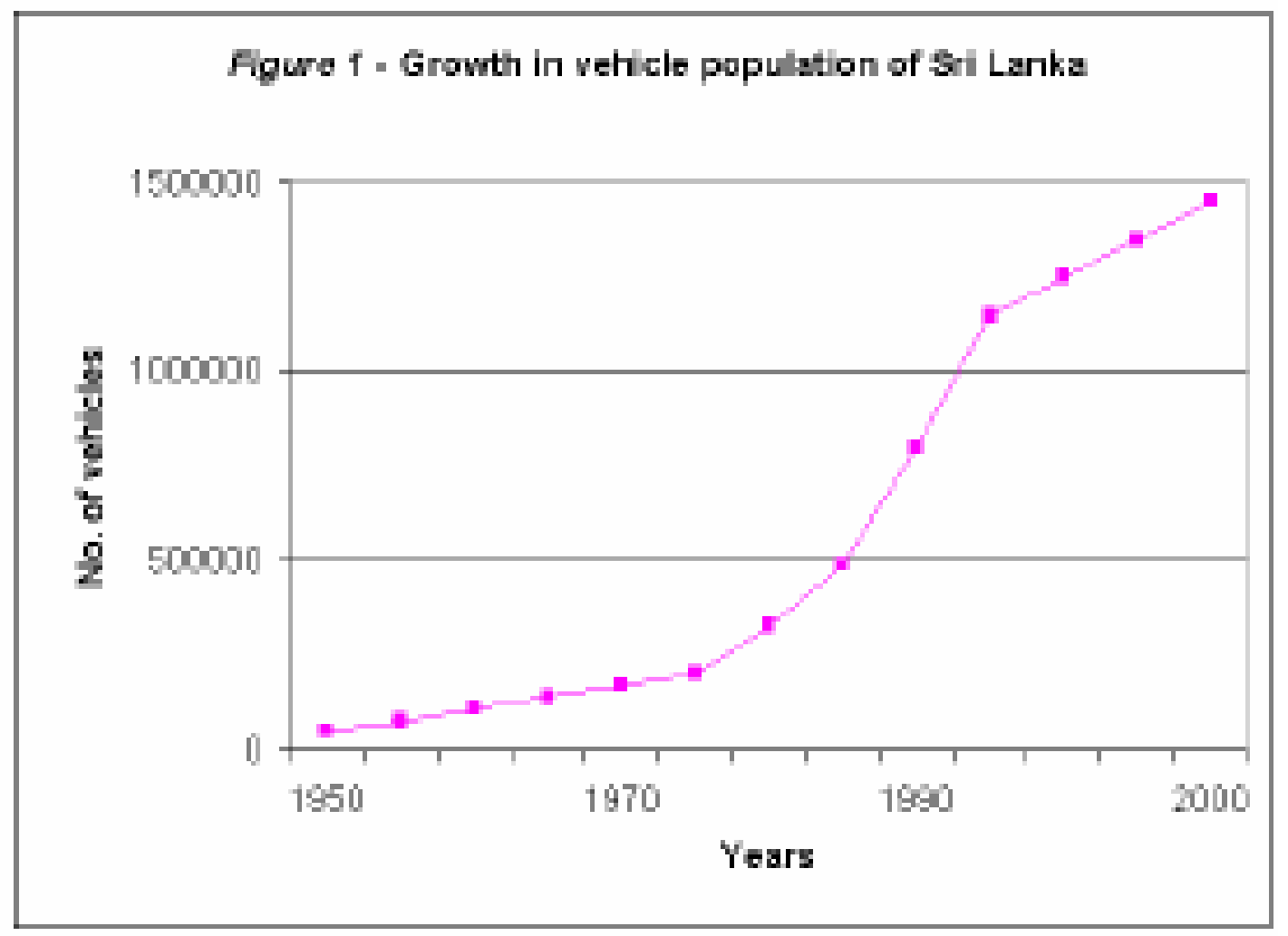

\section{Lead exposure of children}

It is known that eighty to ninety percent of lead in air is from automobile emissions. Lead is a cumulative, protoplasmic poison that affects health in numerous ways. The best known hazard is its effect on the neurodevelopment of children. Following the widely publicized and pioneering research of Needleman this is known to take place even at low levels of exposure $^{8}$.

Lead levels are high in traffic policeman, three wheeler drivers and street vendors in Colombo ${ }^{9}$. But levels in children were unknown. We therefore carried out a study on the blood lead levels of children in Colombo, in 1998 when tetraethyl lead was in use as an antiknock agent in petrol. The study sample comprised 50 apparently healthy children (25 girls and 25 boys), aged one to 15 years, domiciled since birth within 0.5 kilometres of Borella junction ${ }^{10}$. This is a junction where five roads with heavy traffic meet. Road-works at the time of this study resulted in considerable traffic congestion. All children studied had assayable lead in their blood stream. The levels increased with age and boys had higher levels than girls (Table 2). Six percent of the children had lead levels greater than $10 \mu \mathrm{g} / \mathrm{dl}$, the level at which environmental intervention is recommended.

Table 2

Blood lead levels by age and sex ${ }^{10}$
Age (years)

$1-5 \quad(\mathrm{n}=25)$
$>5-10 \quad(\mathrm{n}=12)$
$>10-15 \quad(\mathrm{n}=13)$

$\operatorname{Sex}$

Boys $\quad(\mathrm{n}=25)$

Girls $\quad(n=25)$

\section{Mean blood lead levels} $(\mu \mathrm{g} / \mathrm{dl})$ and SD

$4.3 \pm 1.9$
$5.5 \pm 1.3$
$6.7 \pm 1.8$
6.1

4.9 
Lead is known to affect cognitive abilities by lowering IQ scores, affecting reading, and behaviour ${ }^{8,11,12,13,14}$. We studied the cognitive abilities of 50 children whose lead levels were known, using a standardized scoring system. With increasing years of schooling the development scores reduced. We documented a statistically significant reduction in cognitive abilities with increasing length of residence in this area and ascendancy of the amount of lead in the blood stream ${ }^{15}$. Children who had lived in this locality for only 5-10 years scored significantly better at both numeracy and literacy, while those resident in the area for $>10$ years had below average developmental scores $(\mathrm{p}<0.05)$. We did not implicate lead per se for this cognitive effect since variables such as social, educational, and excessive noise levels could have contributed to this observation.

In 2002, both Sri Lanka and Pakistan changed completely to unleaded gasoline and the entire SAARC region is now "lead free" from gasoline additives. The National Building Research
Organisation in Colombo has demonstrated a drastic drop in road-side atmospheric lead ${ }^{16}$. Has a significant change occurred in blood lead levels of children as a result of this lowered atmospheric lead?

Lead has a half-life of 25-50 days in the blood stream and soft tissue. One year after termination of the use of leaded petrol in Sri Lanka, we reassessed blood lead levels. Forty apparently healthy children from the same location (near Borella junction) were investigated for the presence of lead in venous blood. They were of the same age and sex structures and socioeconomic backgrounds as those in the previous study. Lead levels in blood were estimated in the same laboratory, by the same technique (atomic absorption spectrometry). We found a statistically significant decline in the cohorts of 1998 and $2003^{17}$ (Table 3). The children no longer had levels above 10 $\mu \mathrm{g} / \mathrm{dl}$. All paediatricians will agree with me that the economic cost involved in changing to unleaded petrol has been worthwhile ${ }^{18}$.

Table 3

Blood lead level before (in 1998) and after the change to unleaded petrol (in 2003) ${ }^{17}$

Age (years)

Blood Lead levels

1998

$$
\begin{aligned}
& 4.3 \pm 1.9(n=25) \\
& 5.5 \pm 1.3(n=12) \\
& 6.7 \pm 1.8(n=13) \\
& \mathbf{5 . 2} \pm \mathbf{1 . 8}(\mathbf{n}=\mathbf{5 0}) \\
& 4.9 \pm 1.4(n=25) \\
& 6.1 \pm 1.7(n=25)
\end{aligned}
$$

$\begin{array}{ll}\text { Below } 5 & 4.3 \pm 1.9(n=25) \\ 6-10 & 5.5 \pm 1.3(n=12) \\ \text { Above } 10 & 6.7 \pm 1.8(n=13) \\ \text { Total } & \mathbf{5 . 2} \pm \mathbf{1 . 8}(\mathbf{n}=\mathbf{5 0}) \\ \text { Girls } & 4.9 \pm 1.4(n=25) \\ \text { Boys } & 6.1 \pm 1.7(n=25)\end{array}$

Interestingly, the United States removed lead from gasoline in the 1970's, not to protect children but to protect the inner lining platinum in the newly introduced catalytic converter of automobiles. In the United States blood lead levels of children dropped from $4 \%$ having above $30 \mu \mathrm{g} / \mathrm{dl}$ in $1975-1980$ to $7 \%$ having above $10 \mu \mathrm{g} / \mathrm{dl}$ by $1991-1994$. This is hailed as a major public health success of the last century ${ }^{19}$.

Although levels decreased our study sample showed some lead remaining in the blood stream. To investigate this finding we combed the surroundings of Borella for lead linked industries but found none.

It is noteworthy that children below 10 years did not show a significant reduction in lead levels and had comparatively higher levels than the older children. This change in pattern of lead exposure is in

$$
2003
$$

$\begin{array}{ll}4.8 \pm 1.7(n=11) & P>0.05 \\ 4.7 \pm 2.0(n=14) & P>0.05 \\ 3.8 \pm 1.7(n=14) & P<0.05 \\ \mathbf{4 . 4} \pm \mathbf{1 . 8}(n=39) & \mathbf{P}<\mathbf{0 . 0 5}\end{array}$

$3.9 \pm 1.0(n=13)$

$4.9 \pm 1.9(n=26)$

agreement with findings abroad. The probable explanation is that lead is a stable heavy metal that remains in household dust and soil with particulate lead entering vegetation and food. Increased mouthing activities of young children and higher gut absorption exposes children of younger ages to a greater risk to particulate lead.

Lanphear tabulates (in his research involving children with $10 \mu \mathrm{g} / \mathrm{dl}$ or less) that every one $\mu \mathrm{g}$ of lead in a decilitre of a child's blood reduces reading scores by 1 point, arithmetic scores by 0.7 points and short term memory scores by half a point. Given the harm that even a miniscule amount of lead can cause to the developing brain, the level in young children should ideally be $0 \mu \mathrm{g} / \mathrm{dl}$. As recently as 2002, the Harvard School of Public Health showed that lead levels at birth impaired mental development at 24 months of 
age. Current interest in lead at birth is reflected in reports from Istanbul, Paris, Montreal, urban and rural USA and India ${ }^{20,21,22,23}$.

Are newborns in Colombo contaminated with lead? There was no data on umbilical cord blood lead in Sri Lanka. Therefore in May/June 2003, a year after the switch over to unleaded petrol, a cross-sectional descriptive study on 24 mother-baby pairs randomly selected from municipality maternity homes, serving a homogenous lower socioeconomic urban population in Colombo, was undertaken. Venous and umbilical cord blood samples of mothers and babies were collected into lead-free containers at delivery and compared for the presence of lead. Only one mother had no lead in her blood. Her baby had no lead either. Seventeen of the 24 newborns were found to have assayable quantities of lead in their blood stream supporting the evidence that lead crosses the placental barrier (Table 4). The mean maternal blood lead level was $3.31 \pm 1.49 \mu \mathrm{g} / \mathrm{dl}$ and the mean umbilical blood level was $0.43 \pm 0.46 \mu \mathrm{g} / \mathrm{dl}$. The correlation between maternal and cord blood lead (correlation coefficient $\mathrm{r}=0.36$ ) was not strong. Therefore we do not recommend estimating fetal lead by measuring maternal blood lead levels ${ }^{24}$.

Table 4

Maternal and umbilical cord blood lead levels ${ }^{24}$

\begin{tabular}{cccc}
$\begin{array}{c}\text { Maternal age } \\
(y r s)\end{array}$ & $\begin{array}{c}\text { Birth weight } \\
(\mathrm{g})\end{array}$ & \multicolumn{2}{c}{$\begin{array}{c}\text { Blood lead levels }(\mu \mathrm{g} / \mathrm{dl}) \\
\text { Umbilical cord }\end{array}$} \\
30 & & & Maternal \\
30 & 2950 & 0 & 0 \\
33 & 2670 & 0 & 1 \\
28 & 2510 & 0 & 1.4 \\
21 & 2650 & 0 & 1.6 \\
32 & 2560 & 0 & 3 \\
30 & 3800 & 0 & 3.4 \\
19 & 2800 & 0 & 4.5 \\
26 & 2850 & 0.1 & 2 \\
25 & 2340 & 0.1 & 2.5 \\
23 & 2560 & 0.1 & 3.5 \\
24 & 2770 & 0.1 & 3.7 \\
32 & 2400 & 0.2 & 5 \\
30 & 2640 & 0.4 & 2.5 \\
30 & 3350 & 0.4 & 4.5 \\
28 & 2850 & 0.4 & 5 \\
33 & 3250 & 0.4 & 5.5 \\
29 & 2930 & 0.6 & 3 \\
21 & 780 & 0.8 & 4.2 \\
31 & 2290 & 1 & 3.5 \\
25 & 2704 & 1 & 3.5 \\
22 & 3010 & 1 & 4.5 \\
24 & 2160 & 1 & 6 \\
30 & 2900 & 1.2 & 3.7 \\
28 & 2550 & 1.5 & 2
\end{tabular}

In a comparative study on human umbilical cord blood lead in two urban centres with differing lead exposures, levels in the lead-free city of Montreal was lower than in Paris where lead was still in use as a gasoline additive at the time of this study. This difference was attributed to fuel quality. It is comforting to know that levels in Colombo were comparable with those of the so called lead-free city $^{25}$.

The mean resident time of lead in trabecular bone is 3 years and in cortical bone 30 years. Studies have confirmed that transfer of lead from bone stores into blood stream increases during pregnancy and lactation. The source of prenatal exposure is maternal bone, endogenous rather than environmental. With such deep and long lasting reservoirs in the mother a complete eradication of lead from the fetus cannot be envisaged in the near future. 
Lead has been around, over the centuries, long before the motor car, due to it's many useful characteristics. Concentrations in deciduous teeth from 2000 BC onwards in the Chezv republic bears testimony ${ }^{26}$ (Table 5). We realise that the story of lead contamination is still not over.

\section{Bronchial asthma and air pollution}

Childhood asthma is on the rise worldwide. In the USA a $160 \%$ rise in asthma in the 0 to 4 year agegroup occurred between 1980 and 1990. This steep incline suggests an environmental cause. Global epidemiology shows the increase in childhood asthma to be most in developed countries and in urban rather than rural communities ${ }^{27,28,29}$. Respiratory disorders rank second among causes of hospitalization at all ages in Sri Lanka ${ }^{30}$.

Table 5

\section{Pb Concentration in deciduous teeth of children in Czech and Slovak republics ${ }^{26}$}

$\begin{array}{lccc}\text { Period / Area } & \text { No. of teeth } & \text { No. of children } & \text { Mean level } \pm S D \\ 2000 \text { BC } & 4 & \text { Nil } & \\ 6^{\text {th }} \text { Century AD } & 17 & \text { Nil } & 0.28 \pm 0.10 \\ 9^{\text {th }} \text { Centuary AD } & 13 & \text { Nil } & 0.41 \pm 0.04 \\ 20^{\text {th }} \text { Century Industrialised City } & 72 & 25 & 0.37 \pm 0.03 \\ \end{array}$

Medical evidence testifying to a link between atmospheric pollution and aggravation of asthma is not always straightforward ${ }^{31,32,33,34,35}$. We carried out a case-control analysis of hospital attendance and ambient air pollutant concentrations correlating the day-to-day variation in hospital attendance for severe wheezing with ambient SO2 and NOX. All children attending the Emergency Treatment Unit of the outpatient department in the Lady Ridgeway Children's Hospital with wheezing requiring nebulization were enrolled over a period of one year (1 July 1998 to 30 June 1999). 30,932 children needed nebulization and the mean daily attendance was eighty five. 10,100 children attending the emergency treatment unit for conditions other than respiratory diseases served as controls ${ }^{36}$.

Hospital attendance was correlated with maximum and minimum levels of SO2 and NOx recorded by the continuous pollution monitor situated in the Fort, Colombo (Table 6). The changing patterns in concentrations of both pollutants were consistent $(\mathrm{r}=>0.6)$.

Table 6

\section{Association of pollutant levels and hospital attendance rates ${ }^{36}$}

Pollutant

Concomitant occurrence in weeks (number of weeks studied) Maximum pollution and maximum
attendance

$\begin{array}{ll}\begin{array}{c}\text { Severe } \\ \text { wheezing }\end{array} & \text { Control } \\ 16(41) & 08(37) \\ 13(47) & 07(43)\end{array}$

Minimum pollution and minimum
attendance

Severe

Control

wheezing

22 (48)

27 (49)
14 (44)

20 (49) 
Pollution data was unavailable in a few weeks due to technical and calibration errors. When the data of weeks with valid data were analysed the nebulization rates were highest on the most polluted days and lowest on the least polluted days.

The Lady Ridgeway hospital caseload is predominantly an urbanized sample of self referrals outnumbering the paediatric caseload of any other hospital in Colombo. It therefore reflects prevalence of childhood wheezing in the community as a whole. We concluded that hospital attendance for acute severe wheezing correlated with fluctuations of ambient air $\mathrm{SO}_{2}$ and $\mathrm{NO}_{2}$ irrespective of temperature, rainfall and wind speed. In 1998/99 air pollution in Colombo had reached a level at which it initiated or aggravated childhood asthma.

Four years of attendance data of childhood wheezing at the Lady Ridgeway Children's Hospital Colombo was studied for a temporal variation. A peak incidence was consistent around July. A lower peak occurred in December/January. Both observations reinforced a direct or indirect role of environmental factors. Considerable speculation regarding causation includes air pollution, respiratory infections, pollen, rainfall or is it some other characteristic of the weather? In the absence of a definite answer a study on pollen counts in Colombo is to be embarked on, in collaboration with the Department of Botany. But we cannot forget that power plants, situated within 10 kilometres from the city, in Sapugaskanda and Kelanitissa, emit thousands of tons of $\mathrm{SO}_{2}$ and $\mathrm{NO}_{2}$ by burning diesel and residual fuel.

\section{Indoor air pollution - the inside story}

Australia, a country with a childhood asthma prevalence that is amongst the highest in the world, reports that the dominant contributor to respiratory health is indoor air pollution. This brings us to the inside story. The population segments most susceptible to air pollution i.e. young children, the sick and the elderly, spend the greater portion of their day indoors, exposed to tobacco smoke, wood smoke, nitrogen dioxide from gas stoves or carbon monoxide from mosquito coils. Is indoor air more polluted than outdoor air in Sri Lanka?

Environmental tobacco smoke (ETS), mould spores, carbon monoxide and mercury vapour - termed the "fatal four" in the USA, are pronounced important for consideration by paediatricians.

WHO estimates that half of the world's households cook with unprocessed solid fuels. One climbs the 'energy ladder' with improvement in socioeconomic status, by burning less harmful fuels. The world's poorest burn bio-fuels: wood, crop residue or dung. In reality, surface area to volume ratios of low income housing units differ markedly from high income houses, with high concentrations of airborne effluents in poorly ventilated living areas.

We carried out a study on indoor pollution in lower middle class homes of five locations in the city of Colombo. Our objective was to estimate indoor, outdoor and personal exposure levels. Five locations were randomly selected out of 15 locations with air quality monitoring stations - Pettah, Mattakkuliya, Maradana, Kirullapone and Borella. One street in each location, situated within $1.5 \mathrm{~km}$ radius from each air quality monitoring station, was utilized to select 30 house-holds (6 per location) by cluster sampling and these households were serially visited to enrol thirty children between 5 and 10 years of age, irrespective of their health status - one child per household. Information on dwelling characteristics, proximity to traffic areas, ventilatory space per floor area per occupant, details of indoor combustion, type of fuel used for cooking, frequency of burning mosquito coils and parental smoking, were gathered by an interviewer-administered questionnaire.

A clip-on passive air-filter badge was given to each child to wear on his/her chest, clipped on to clothing during all waking hours with instructions to place the monitor on a table/chair during meal times, bath times and when sleeping. The passive air filter badges measured personal exposure to $\mathrm{NO}_{2}$ and $\mathrm{SO}_{2}$. A similar sampler was placed in the living area of each home, at least 2 metres away from open windows. Another monitor was placed outside the house and its recordings were compared with ambient air $\mathrm{NO}_{2}$ and $\mathrm{SO}_{2}$ concentrations measured at the nearest monitoring station. All outdoor, indoor and personal samplers were exposed for the 48 consecutive hours, sealed and transported to the laboratory for analysis. The parents maintained a daily activity diary consisting of half-hour time bands for waking hours and one hour time bands for sleeping hours, during the two day sampling period, and recorded mode, duration and description of travel during this study period.

We assessed the respiratory health of all children in these households. We found that only $6.9 \%$ of households were adequately ventilated and parental tobacco smoking took place inside $38 \%$ of households. $62.6 \%$ of households used mosquito coils. Fuel used was firewood by $14 \%$, kerosene by $28 \%$ and gas by $66 \%$ for cooking; and $8 \%$ used both 
gas and kerosene. None used dung or crop residue as cooking-fuels. Measured pollutant levels from the indoor, outdoor and personal exposure monitors, showed the indoor levels to be higher than outdoor levels. The mean indoor to outdoor ratio ( $\mathrm{I} / \mathrm{O}$ ratio) was greater than one in all five areas (Table 7). We concluded that air inside lower middle class homes in Colombo is more polluted than outdoor air. Data on indoor air pollution should be considered in drawing conclusions on exposure response relationships on respiratory health.

\section{Table 7}

\section{Indoor: outdoor pollution ( I/O ratio) in Colombo}

\section{Mean I/O}

$\begin{array}{lc}\text { Pettah } & 1.39: 1 \\ \text { Mattakkuliya } & 1.13: 1 \\ \text { Borella } & 1.11: 1 \\ \text { Maradana } & 1.78: 1 \\ \text { Kirulapone } & 2.04: 1\end{array}$

The time spent indoors by the children was on the average 41 hours out of 48 hours. The average time spent outdoors was only 6.8 hours over the two days (Saturday and Sunday). Most of the outdoor time was in close proximity to the home with only 2 hours being spent away from the home. $72.6 \%$ of the daylight hours (0630 hrs to $1830 \mathrm{hrs}$ ) on these two holidays (Saturday and Sunday) had been spent indoors (Table 8). Is this a consequence of television? $27.6 \%$ of the daylight hours was accounted for outdoors. These statistics on activity patterns of children further highlights the need for attention to indoor air. During weekdays the classroom air would need studying.

Table 8

Daily activity patterns -5 - 10 year olds (Saturday and Sunday)

$\begin{array}{lc} & n=29 \\ \text { Time spent indoors } & 41.18 \mathrm{hrs} / 48 \mathrm{hrs} \\ \text { Time spent outdoors } & 6.83 \mathrm{hrs} / 48 \mathrm{hrs} \\ \text { Away from home } & 2.03 \mathrm{hrs} / 48 \mathrm{hrs}\end{array}$

\section{Daylight hours (0630 - 1830 hrs)}

$\begin{array}{ll}\text { Outdoors } & 27.35 \% \\ \text { Indoors } & 72.64 \%\end{array}$

A recent study on risk factors for major congenital malformations carried out in the De Soysa Maternity Hospital for Women in Colombo has found the burning of mosquito coils within the bedroom to be a significant risk factor. But market surveys show mosquito coils heading the shopping lists of consumables purchased daily by the residents of Colombo $^{37}$.

Why are children particularly at risk of air pollution?

Children have physiological and behavioural characteristics that make them particularly vulnerable. The relatively high metabolic rate and oxygen requirement causes the resting minute ventilation (in relation to body size) to be higher in children. The amount of air exchanged between the lungs and the environment per kilogram body weight is more than double in newborn infants $(400 \mathrm{ml} / \mathrm{min} / \mathrm{kg})$ when compared with adults $(150 \mathrm{ml} / \mathrm{min} / \mathrm{kg})$. Children are closer to ground level and at increased exposure to bio-allergens, air borne irritants and ground ozone. The narrowed posterior pharyngeal airway by adenoidal and tonsillar hypertrophy in the 4 to 9 year age group encourages mouth breathing exposing the lower respiratory tract to large particulate matter in inspired air. Resistance to air flow in tubular structures is determined by the radius of the tube and the viscosity and density of the gas. The small size of airways causes greater exposure to pollutants in inhaled air. Among behavioural activities of children that expose them to air pollutant are mouthing of objects and being exposed to traffic in the peak hours.

I conclude recommending that fuel quality, vehicle emission standards and lead linked industries be monitored and bio-monitoring programmes be implemented to safeguard women and infants from in-utero contamination by occupational and other environmental pollutants. Research is needed to describe indoor pollutants, identify sources, set safety standards, and recommend environmental interventions. Ventilation inside low income households needs improvement. Safety standards for air quality are stipulated only for outdoor air although children spend most of their day indoors. Paediatricians do not have guidelines for recognizing a given exposure to a pollutant as a health risk. It is essential that clinical evidence is gathered to make this possible. 
I will end recalling the words of the greatest environmentalist of all, as stated in the Paraloka Sutta,

"Thesan adhamma raga rattanan

Devo na sammadaran

Dubbikkhan hothi, dussassan, setattikan salaka

Puttam thena bahu manussa kalan karonthi",38

Unnatural actions will pollute the atmosphere with impurities and heat

Driving away deities and beneficial factors

Causing famine to follow drought and loss of vegetation

Resulting in the death of children of many persons.

This warning was issued over twenty five centuries ago but has gone unheeded. Let us work for a meaningful change because safe air is as important as safe water and safe food for children.

\section{References}

1. Ministry of Health. Mortality \& morbidity during the London fog of December 1952 London: HMSO 1954 (Report on public health and medical subjects. No 95).

2. Lowther P J, Waller R E. Physical Hazards In: Paediatrics and the Enviornment, Editor Donald Barltrop. Fellowship of Postgraduate Medicine. London 1975.

3. WHO Bulletin 2002. 80 (12).

4. Bruce N, Perez-Padilla R, Albalak, R. The health effects of indoor air pollution exposure in developing countries. Protection of the Human Enviornment. WHO Geneva 2002.

5. Samarakkody R P, Yalegama $M \quad S \quad B$, Aluthwala P N. Some aspects of air pollution in Colombo city. Proceedings of the Commonwealth Science Council Workshop on Acid rain monitoring and atmospheric modeling, University of Peradeniya, Sri Lanka 1998: 20-26.

6. Lvovsky K. Objectives and overall achievements of the Urban Air Quality Management Programme. World Bank. Paper presented at Disseminated Workshop of UAQMP Colombo, 2003.

7. Kojima N. International experience in air quality management. Paper presented at Disseminated Work-shop of UAQMP Colombo, 2003.
8. Needleman H I, Schell A. Bellinger D, Levinton A, Allred E N. Long effects of exposure to low doses of lead in childhood. 11 year follow up report. New England Journal of Medicine 1992; 322: $83-8$.

9. Arewgoda M. Assessment of blood lead levels of the population exposed to vehicle emission, Paper presented at natural resources and enviornmental policy project, NAREPP/IRG 1993.

10. Amaratunge S, Sumanasena S P, Hubert H D M, Senanayake M P. Blood lead levels of children living near Borella junction. Ceylon Medical Journal 2001; 46:111.

11. Fulton M. Influence of blood lead on the ability and attainment of children in Edinburgh. Lancet 1987; 2: 1221-6.

12. Schwartez J. Low level lead exposure and children's IQ: a meta analysis and search for a threshold. Environmental Research 1994; 65: 42-55.

13. Good M I. Long term effects of exposure to low doses of lead in childhood. New England Journal of Medicine 1991; 324: 415-8.

14. Faust D, Brown J. Moderately elevated blood lead levels: effects of neurophysiological functioning in children. Pediatrics 1987: 623-9.

15. Senanayake M P, Sumanasena S P. Cognitive development of lead exposed children near Borella junction. Sri Lanka Journal of Child Health 2003; 32: 15-7.

16. Changing atmospheric lead levels in Colombo with discontinuation of leaded petrol in Sri Lanka. A report by Environmental Division of National Building Research Organization, Colombo, Sri Lanka, February 2003.

17. Senanayake M P, Rodrigo M D A, Malkanthi R. Blood lead levels of children before and after introduction of unleaded petrol. Ceylon Medical Journal 2004; 49: 60-1.

18. Landrigand P J. The worldwide problem of lead in petrol. Editorial; WHO Bulletin 2002; 80: 10. 
19. Piomelli S, Childhood lead poisoning. Pediatric Clinics of North America 2002; 49: 1285-304.

20. Furman A, Lalely. Maternal and umbilical cord blood lead levels: an Istanbul study. Archives of Environmental Health 2001; 56: 26-8.

21. Chuanbg H Y, Schwartz J, Gonzales-Cossio T, Lugo M C. Interrelations of lead levels in bones, venous blood and umbilical cord blood with exogenous lead exposure through maternal plasma lead in peri partum women. Environmental Health Perspectives 2001; 109: 527-32.

22. Gomaa $\mathrm{A}, \mathrm{Hu} \mathrm{H}$, Bellinger D. Maternal bone lead as an independent risk factor for fetal neurotoxicity a prospective study. Pediatrics 2002; 110: 110-8.

23. Gardella. Lead exposure in pregnancy: a review of the literature and argument for routine prenatal screening. Obstetrics and Gynaecological Survey 2001; 56: 231-8.

24. Senanayake M P, Rodrigo $M$ D A, Kudalugodaarachchi J. Umbilical cord blood levels: a Colombo study. Ceylon Medical Journal (in press).

25. Smargiassi A, Takser L, Masse A, Sergerie M, Mergler D, St-Amour G. Comparative study of manganese and lead levels in human umbilical cord and maternal blood from two urban centres exposed to different gasoline additives. Science of Total Environment 2002; 290: 157-64.

26. Valdimir Bencho. Lead concentrations in deciduous teeth of children in Czech \& Slovak republics, Institute of Hygiene \& Epidemiology. Charles University, Prague.

27. Burr M L, Butland B K, King S, VaughnWilliams E. Changes in asthma prevalence: two surveys 15 years apart. Archives of Disease in Childhood 1989; 64: 1452-6.

28. Bronchial asthma, Weekly Epidemiological Report - Ministry of Health, December 1998; (26) 52.
29. Ninan T K, Russel G. Respiratory symptoms and atopy in Aberdeen school children: evidence from two surveys 25 years apart. British Medical Journal 1992; 304: 873-5.

30. Annual Health Bulletin, Ministry of Health Colombo 1997: 22.

31. Buchdahl R, Parker A, Stebbings T, Babker A. Association between air pollution and acute childhood wheezy episodes: Prospective observational study. British Medical Journal 1996; 312: 661-5.

32. Waldron G, Pottle B, Dod J. Asthma and the motorways - one district's experience. Journal of Public Health Medicine 1995; 17: 85-9.

33. Strachan D P. Traffic exposure and asthma: problems of interpretation, British Medical Journal 1996.

34. Livingstone A, Shaddick G, Grundy C, Elliott P. Do people living near inner city main roads have more asthma needing treatment ? Case-control study. British Medical Journal 1996; 312: 676.

35. Weiland S K, Nundt K A, Ruckman A, Keil U. Self reported wheezing and allergic rhinitis in children and traffic density on street on residence. Annals of Epidemiology 1994; 49: 223-7.

36. Senanayake M P, Samarakkoddy $R$ D, Sumanasena S, Kudalugodaarachchi J, et al. A relational analysis of acute wheezing \& air pollution. Sri Lanka Journal of Child Health 2001; 30: 66-8.

37. De Silva M V C, et al. Risk factors associated with major congenital malformations occurring at DMH. Personal communication.

38. Paraloka Sutta, Thika nipatha 97. Anguttara Nikaya. 
